\title{
Application of Nanomaterials in Water Purification: A review
}

\author{
Khalida F. AL-Azawi1 ${ }^{1}$, Shaimaa AL-Baghdadi' ${ }^{2}$ Shemaa A.Soud ${ }^{3 *}$ \\ 1- Applied Chemistry Division, Applied Science Department, University of Technology,Iraq \\ 2- Energy and Renewable Energies Technology Centre, University of Technology, Iraq \\ 3- Biotechnology Division, Applied Science Department, University of Technology, Iraq \\ (100234@uotechnology.edu.iq)
}

\section{Article Information}

Received: 24/12/2020

Accepted: 10/02/2021

\section{Keywords:}

Nanotechnology,Nanomaterial, Photocatalysis, Water pollution, and Contaminants.

\begin{abstract}
Providing clean water all over the world at low cost to meet human needs is a big challenge in the current century. As the world strives to keep pace with the increasing demand for clean water as quickly as possible due to the permanent increase in population density and the deterioration of the state of water and its quality in addition to climate changes. The requirement for developing technological innovations incorporated water managing can't be exaggerated. As reached by previous researchers, nanotechnology possesses vast capabilities to improve water treatment and purify it from organic and inorganic pollutants through the safe use of unconventional water sources. This review covers the methods that have been examined both laboratory and commercially in purifying and treating water. This research provides a discussion of the used methods, advantages and their limitations and also covers a study of nanomaterials used as photocatalysts, whether manufactured or under study. This is done by studying and reviewing the chemical and physical properties of these nanomaterials and their applications in treating water pollution.
\end{abstract}

\section{Introduction:}

Water is the most fundamental substance for all life on earth and a valuable asset for human development. the most essential humanitarian challenges included the credible access to clean water for the 21st century [1]. Growth of industry worldwide has massively expanded the waste by-products generation and cumulation. Conventional removal procedures of industrial wastes increased the groundwater toxicity [2]. Human society is confronting a main environmental issue as a result of the mentioned methods used by factories to dump their waste and their role in polluting water [3]. Globally, WHO has reported that about 3.7 million of population have passed away in 21st century because of ecological contamination. Water pollution by organic chemical compounds is counted to be a difficult issue since it influences the earth, living beings, and human wellbeing, yet in addition as a result of economic activities regarding with water usage [4]. Several water contaminants with organic compounds assuming the significant role [5]. Numerous sorts of organic chemical compounds, for example, pesticides, phenols, polycilic-aromatic hydrocarbons (PAHs), aliphatic and 
hetercyclic compositions and industrial and rural productions just as the individuals living could be the wastewater sources imperiling water safety [6]. Where the simpler the pollutant structure, the easily degraded in environment [7] like methanol and polysaccharide [8], while persistent organic pollutants are hardly to degrade [9] 'Fig. 1'. The latter pollutants kind is a lipid soluble and cancer-causing, teratogenic, and neurotoxic [10]. In summary, various nanoscale materials have been developed like zeolites, nano sorbents, nano catalysts, dendrimers and nanostructured catalytic membranes to be useful in disinfection diseases resulting microorganisms, organic and inorganic solutes and removal of toxic substances from water. There are several efficient processes called membrane processes [11], the principle of which is to work with pressure-driven filtration [12] to remove large amounts of pollutants such as microfiltration [13], ultrafiltration [14], reverse osmosis [15] and nanofiltration [16]. And so, remedying of risky waste materials from water has become a subject the global priority, in this review we are focusing on water contaminations and the most valuable technique to limit it. This work will discuss the adopted methods, advantages and their limitations and also covers a study of nanomaterials used as photocatalysts, whether manufactured or under study.

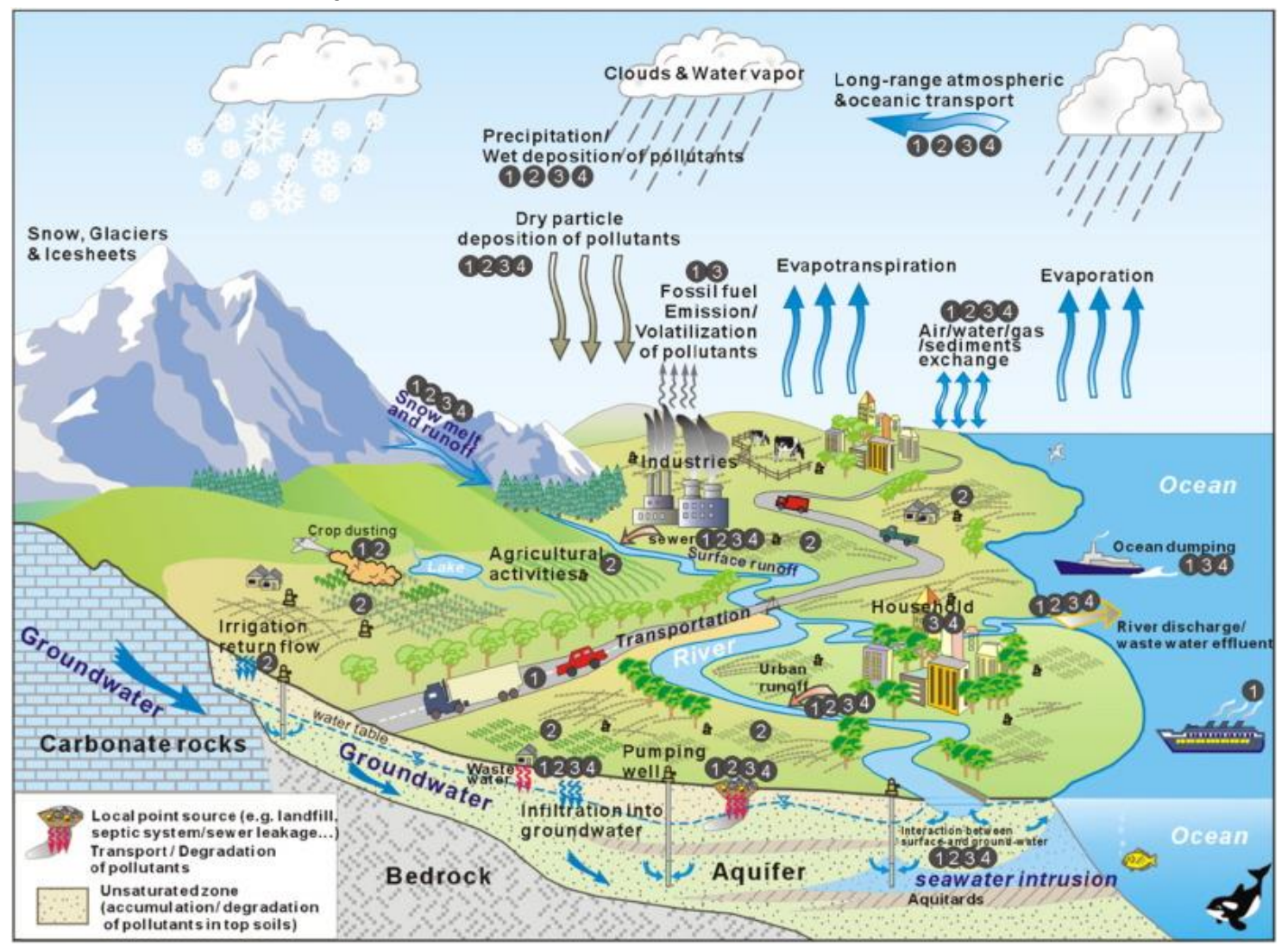

Fig 1. Persistent organic pollutants in China's surface water systems [10].

\section{Nanotechnology for water purification}

Nanotechnology providing an efficient innovative solution in treating of water pollution issues identified with quantity and quality. Nanomaterials such as carbon nanotubes and dendrimers contribute to develop of progressively productive treatment processes among the developed water systems [17]. The advanced trade and non-trade techniques are used dayby-day, since the invention of nanotechnology in water purification till now proves its effectiveness in water treatment [18]. Advancements in researches of using the nanotechnology have made it conceivable to create financially achievable and naturally stable treatment innovations for viably treating water meeting the standards of water quality [19]. 
Sufficiently, many issues of water quality can be addressed by various nanoparticle types or nanofibers. Nanoparticles treat water because it can penetrate deeper [20]; for example removing Hg from Erbo river as illustrated in 'Fig. 2' [21]. Nanomaterials are characterized by several features that help in water purification, such merts are as follows:

a. Nanotechnology utilizes materials of at least one-dimension size $<100 \mathrm{~nm}$ as seen in the scanning electronic microscopic pictures in 'Fig. 3' [22].

b. Higher surface to volume ratio of nanoparticles improves the reactivity with pollutants [23], and offering treatment and remedying, detecting and pollution preventing [24].

c. There are different types of nanomaterials:

i. Zero dimensional nanoparticles (at a single point has a fixed length, breadth and height) such as nano dots like carbon-based quantum dot used in water purification [25].

ii. One dimensional nanoparticle where it can have just one parameter for instance graphene [26].

iii. Two dimensional where it only possess length and breadth for instance carbon nanotubes [27].

iv. Three dimensional where it has all the parameters, for example, length, expansiveness and stature for instance graphene based hybrid materials for treating water [28].

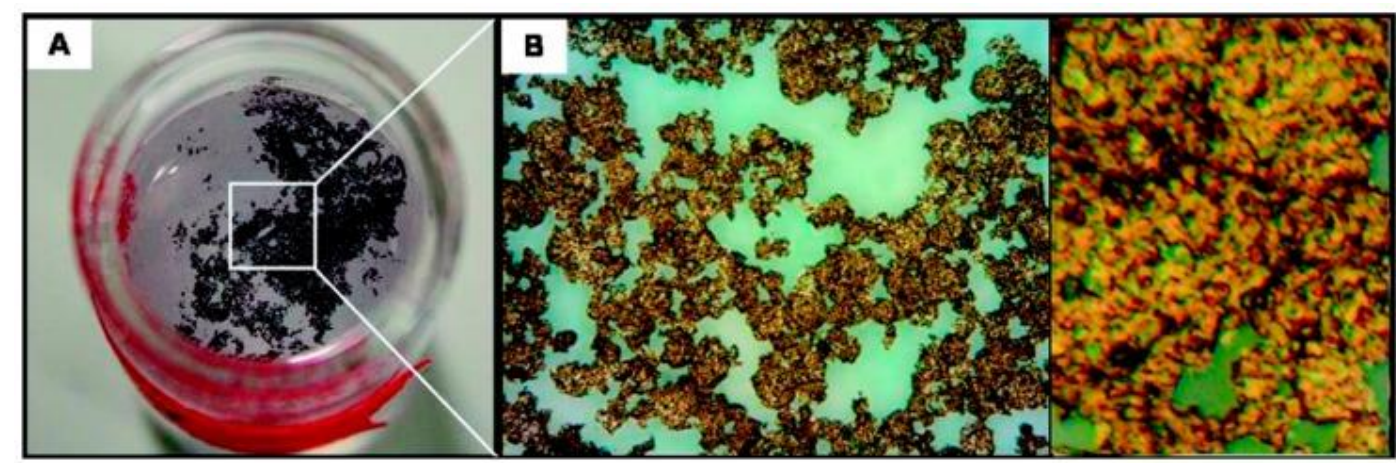

Fig 2. Hg removal from Erbo river: A. result of treating by $\mathrm{Hg}$ with $\mathrm{Au}$-nanoparticles and $\mathrm{B}$. $40 \times$ magnified optical microscope image [21].

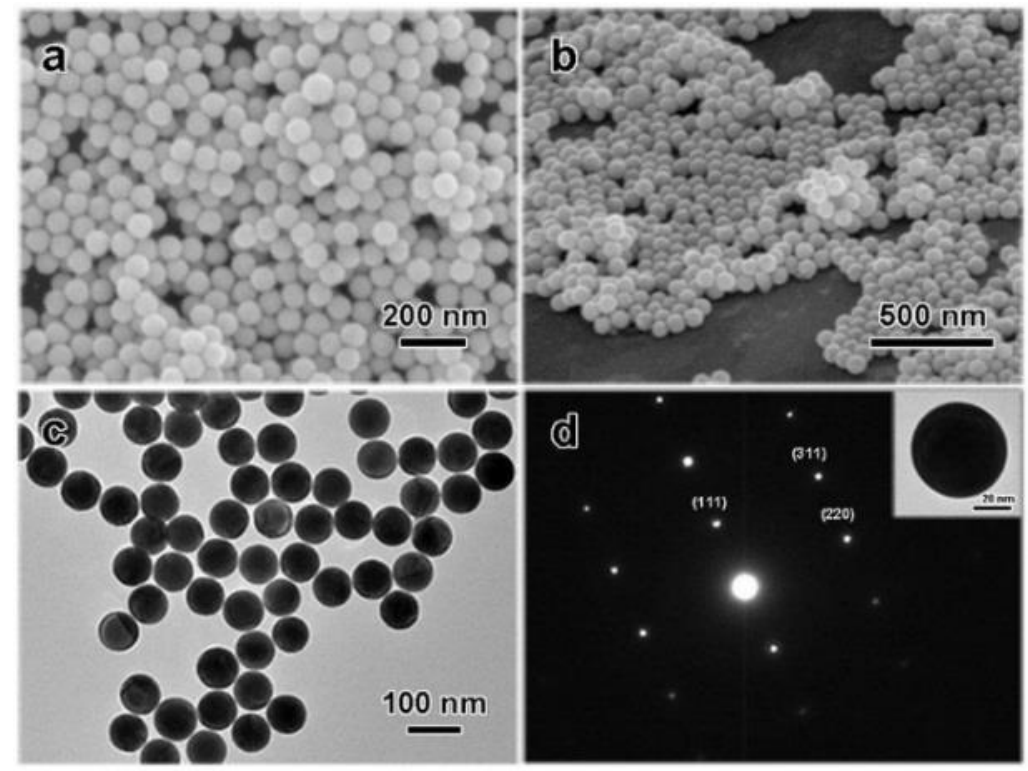

Fig 3. Scanning electron microscopic images of Au spherical nanoparticles [22]. 
The nanoparticles are of various shape, size and structure [29]. The forms of crystalline or amorphous nanoparticles differ from each other shape, including cylindrical, conical, spherical, flat and others with a regular or irregular surface with respect to surface variation [30]. Various union strategies are either being advanced or improved to upgrade the properties for low cost productions. Modification of these methods is to accomplish process explicit nanoparticles to expand their optical, mechanical, physical and concoction properties [22]. The nanoparticles are currently utilized in each item like from cooking vessel, hardware to renewable energies, aerospace industry and etc.

Nanotechnology is the key for a perfect and maintainable future. Different types of nanoscale materials such as titanium dioxide [31], carbon nanotubes [32], zinc oxide and doped-zinc oxide and so forth [33] were examined and used commercially and by researchers in water treatment are illustrated in 'Fig. 4' with different analysis methods [34]. Nanomaterials has been used in water purification and laboratory experiments have been conducted on these materials to remove pollutants from the water, and they have given successful results such as graphene oxide to remove toxic ions pollutants [35], graphene based material used to remove heavy metal radionuclides [36], carbon nanotubes used to remove heavy metals and organic contaminants [27], the bioactive nanoparticles to remove the bacteria, the biomimetic membranes to remove salts from water and so on. Above, membrane techniques are mentioned as a method of water treatment.

Nanomaterials contributed to the development of these filtration processes and made them more efficient and on the other hand made them affordable in terms of cost [37]. Nanoparticles have been as often as possible utilized in membrane fabricating by either blending gathering nanoparticles into porous membrane to allow controlling the permeability and fouling resistance in different structures and significant functionalities [38]. Finally, nanofibrous media [39] have also been used to improve the filtration systems due to their high permeability and small pore size properties [40]. They are synthesized by a new and efficient fabrication process, namely, electrospinning and may exhibit different properties depending on the selected polymers [41].

\section{Water purification methods}

During the past three decades, the problems of chemical and biological pollutants in water have received wide attention from researchers all over the world in this field in order to reduce the amount of pollutants and toxins in the water in several ways [42]. The conventional methods 'Fig. 5'are distillation method [42], chemical transformation, coagulation and flocculation, biological treatment [43], ultraviolet treatment, reverse osmosis [15], nanofiltration [40], ultrafiltration, microfiltration and carbon filter. The comparison between the nanofiltration and reverse osmosis membranes in water purification application two methods proves that the first method is more affordable than the second one. Both methods are efficient in salts, ions, bacteria, molds and minerals removal. In water purification processes, ultrafiltration membranes are used, colloids and large particles are removed as shown in 'Fig. 6' [14]. On the other hand, microfiltration membrane is considered as the most mature process depending on liquid filtration. 
There are still some challenges for scientists to improve the manufacture of these methods and get rid of their weaknesses in terms of reducing osmotic pressure, the problem of limited porosity and others [44]. Basically, a membrane is a barrier which separates two phases from each other by restricting movement of components through it in a selective style [42]. Characteristically, membranes can be classified as isotropic or anisotropic. Isotropic membranes are uniform in composition and physical structure. They can be microporous; in which case their permeation fluxes are relatively high compared to when they are nonporous (dense) where their application is highly limited due to low permeation fluxes. Isotropic microporous membranes are widely applied in microfiltration membranes. Anisotropic membranes on the other handare non-uniformover the membrane area and are made up of different layers with different structures and composition. These membranes have a thin selective layer supported by a thicker and highly permeable layer. They are particularly applied in reverse osmosis (R0) processes [37].The major disadvantages associated with such purification methodologies are listed in Table below:

Table 1. The major disadvantages of available water purification methods.

Method

\begin{tabular}{ll}
\hline Distillation & $\begin{array}{l}\text { It requires high energy and a large amount of water to remove pollutants, } \\
\text { and most pollutants remain. Pollutants with a boiling point greater than } \\
100^{\circ} \mathrm{C} \text { are difficult to remove. }\end{array}$ \\
\hline $\begin{array}{l}\text { Chemical } \\
\text { transformation }\end{array}$ & $\begin{array}{l}\text { It needs additional reagents. The compound can be of low quality, } \\
\text { environmentally invalid, and difficult to activate in the harsh } \\
\text { environment. }\end{array}$ \\
\hline Biological & $\begin{array}{l}\text { It is difficult to monitor the sensitivity of major groups of microorganisms } \\
\text { to the environmental conditions. It is may be damaged by the } \\
\text { intermediates, time consuming and very expensive method }\end{array}$ \\
\hline Reverse & $\begin{array}{l}\text { It works to remove minerals and leave behind an acidic environment and } \\
\text { requires a high amount of energy. This method does not work when } \\
\text { chemical, chloramine, and volatile organic and others are required to be } \\
\text { removed }\end{array}$ \\
\hline In addition to the high energy required, this technique always requires \\
pre-treatment. At a specific lifetime, the membranes are spoiled and this \\
technique is expensive for this reason. \\
\hline Ultrafiltration
\end{tabular}

\section{Disadvantage}




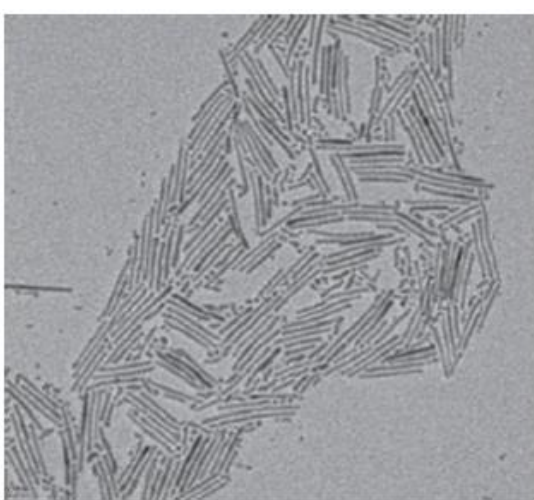

(a) TEM image of $\mathrm{TiO}_{2}$ nanocrystals

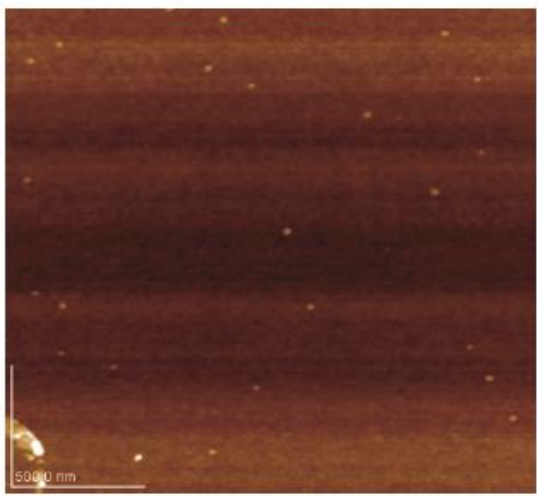

(c) AFM image of Zinc oxide ( $\mathrm{ZnO})$ nanoparticles

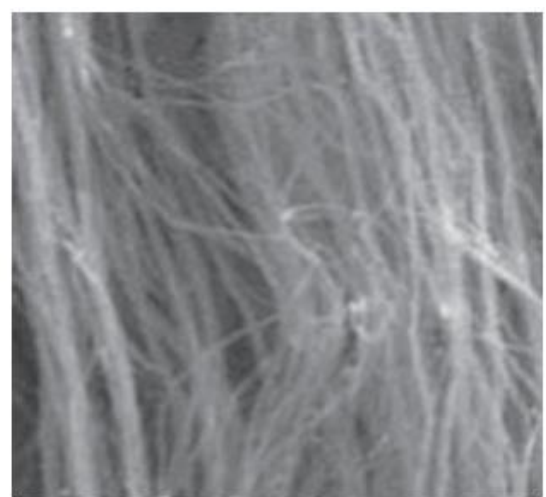

(b) SEM images of aligned CNTs

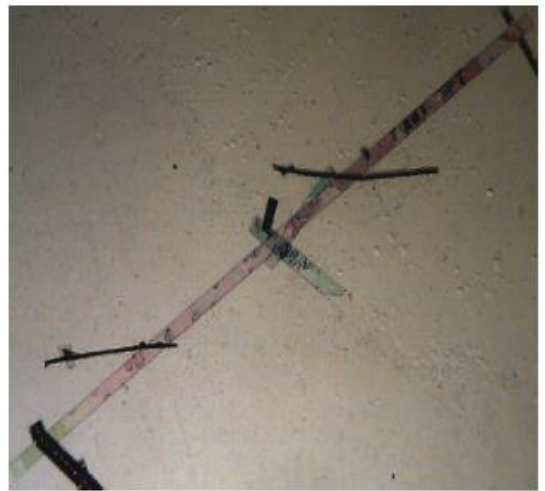

(d) Optical microscope image of Sn-doped $\mathrm{ZnO}$ nanobelts

Fig 4. Examples of different types of nanomaterials including particles, crystals, tube, and belts [34].

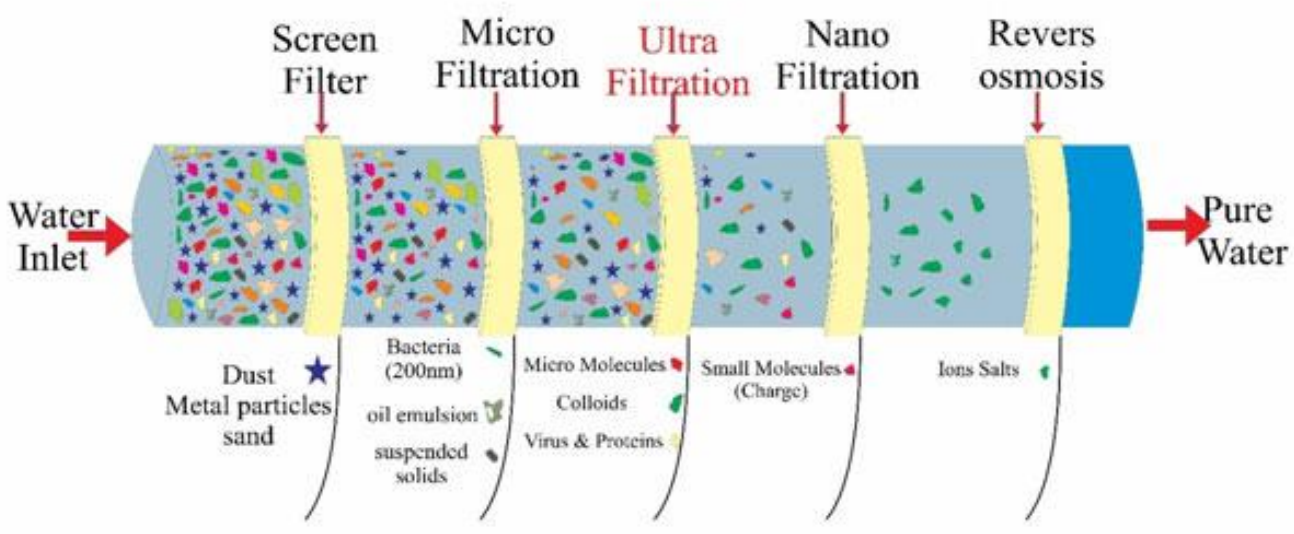

Fig 5. Types of Filteration methods for water purification 


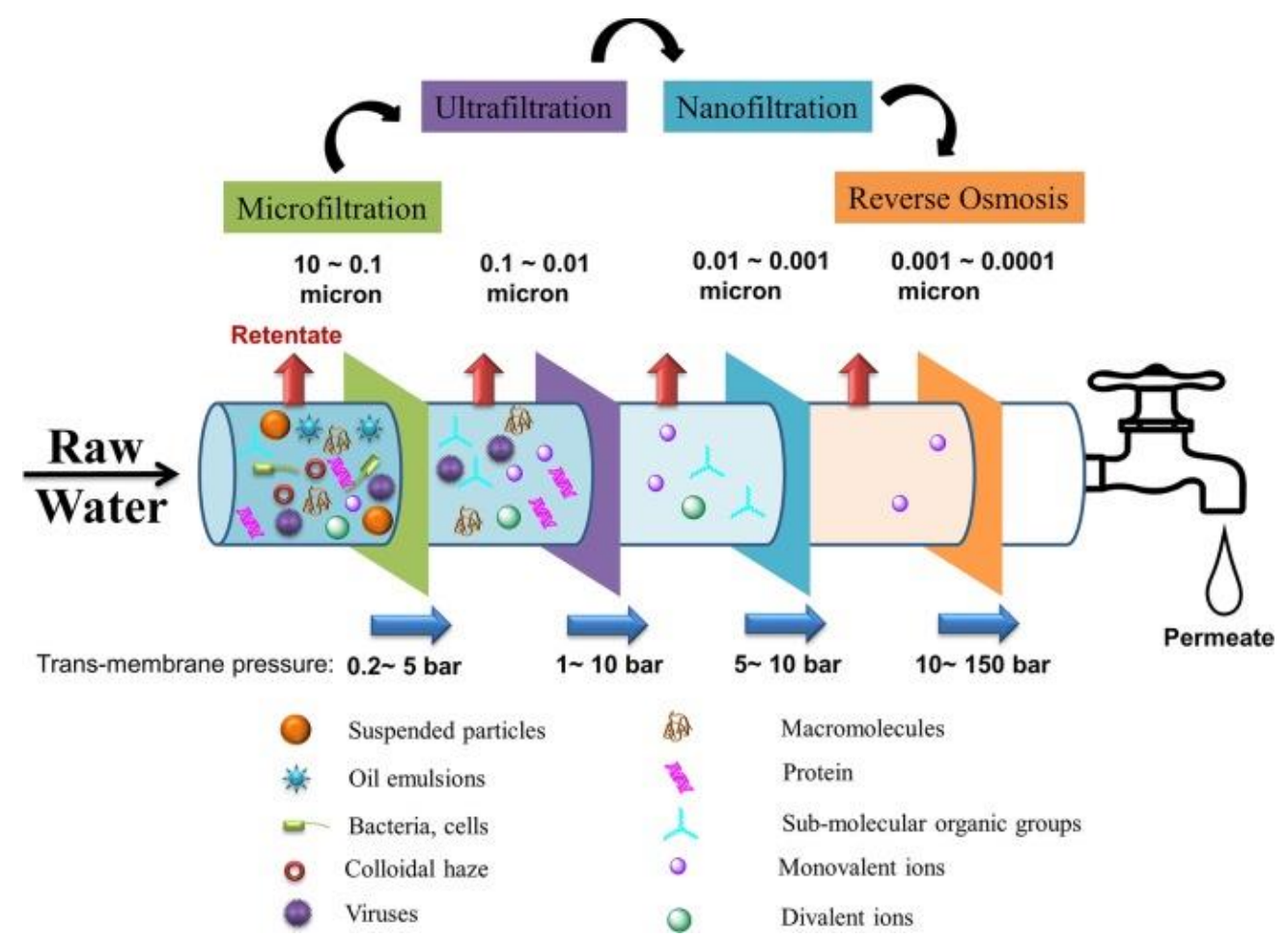

Fig 6. prograss of filteration methods of pollutant removal [14].

\section{Semiconductor photocatalysis}

Recently due to the potential energy and energy gap energy of each semiconducting material, these materials have received a significant interest in photocatalysis applications "Fig. 7a'. [45]. The perfect semiconductor photocatalyst materials are defined by their core component enable the material to change its valence state reversibly to suit a hole and keep the semiconductor from being decomposed, for example, $\mathrm{Ti}^{3+} \rightarrow \mathrm{Ti}^{4+}$ in nonstoichiometric $\mathrm{TiO}_{2}$ [46]. The photogenerated gaps ought to be highly oxidized to create hydroxyl radicals $(\cdot \mathrm{OH})$ and the photogenerated electrons ought to decrease enough for production of superoxide from oxygen atoms [47]. Likewise, the semiconductor ought to have a suitable bandgap and more than one stable valence so the elements are not decomposed by holes production (e.g., $\mathrm{Zn}^{2+}$ in $\mathrm{ZnO}$ and $\mathrm{Cd}^{2+}$ in $\mathrm{CdS}$ are photo-corroded by holes production [48].

\subsection{Mechanism of photocatalysis}

The semiconductor photocatalysts have a void or null region that extends from valence band (VB) to the conduction band (CB), that represented by the top of highest occupied molecular orbital (HOMO) to the bottom of lowest unoccupied molecular orbital (LUMO) [49]. This region known as band gap denoted by Eg. At illumination states, the semiconductor absorbs a photon of energy (hv). If the photon energy $\geq \mathrm{Eg}$, an electron is promoted from $\mathrm{VB}$ to CV leaving a hole instead in the original place 'Fig. 7b'. The generated e--hole pairs then migrate to the photocatalyst material surface where several processes may occur like recombination, energy dissipation or reaction with donor or accepter electrons on semiconductor surfaces or other processes [50].

In general, a hydroxyl radical is formed from water oxidizing by holes, then a chain of reactions will start that proceeds for organics oxidization while the electrons can be donated to electrons acceptors. Therefore, semiconductors are considered as a basic material in photosynthetic stimulation of decomposition of organic compounds and removal of ions to 
treat water pollution, as when using TiO2 nanoparticles [51], which have demonstrated activity in photosynthesis, protective coatings and solar cells sensitive to dye [52]. The previous researches have proved the efficiency of the three phases of TiO2; anatase (A) [53], rutile (B) and brookite (B) [54]. For example, the sol-gel method and a hydrothermal technique were utilized to develop Fe3+-modified TiO2 photocatalyst. The gained phase by the first method was highly crystalline anatase phase while a reduction in crystallinity was observed when the second method was applied [55].

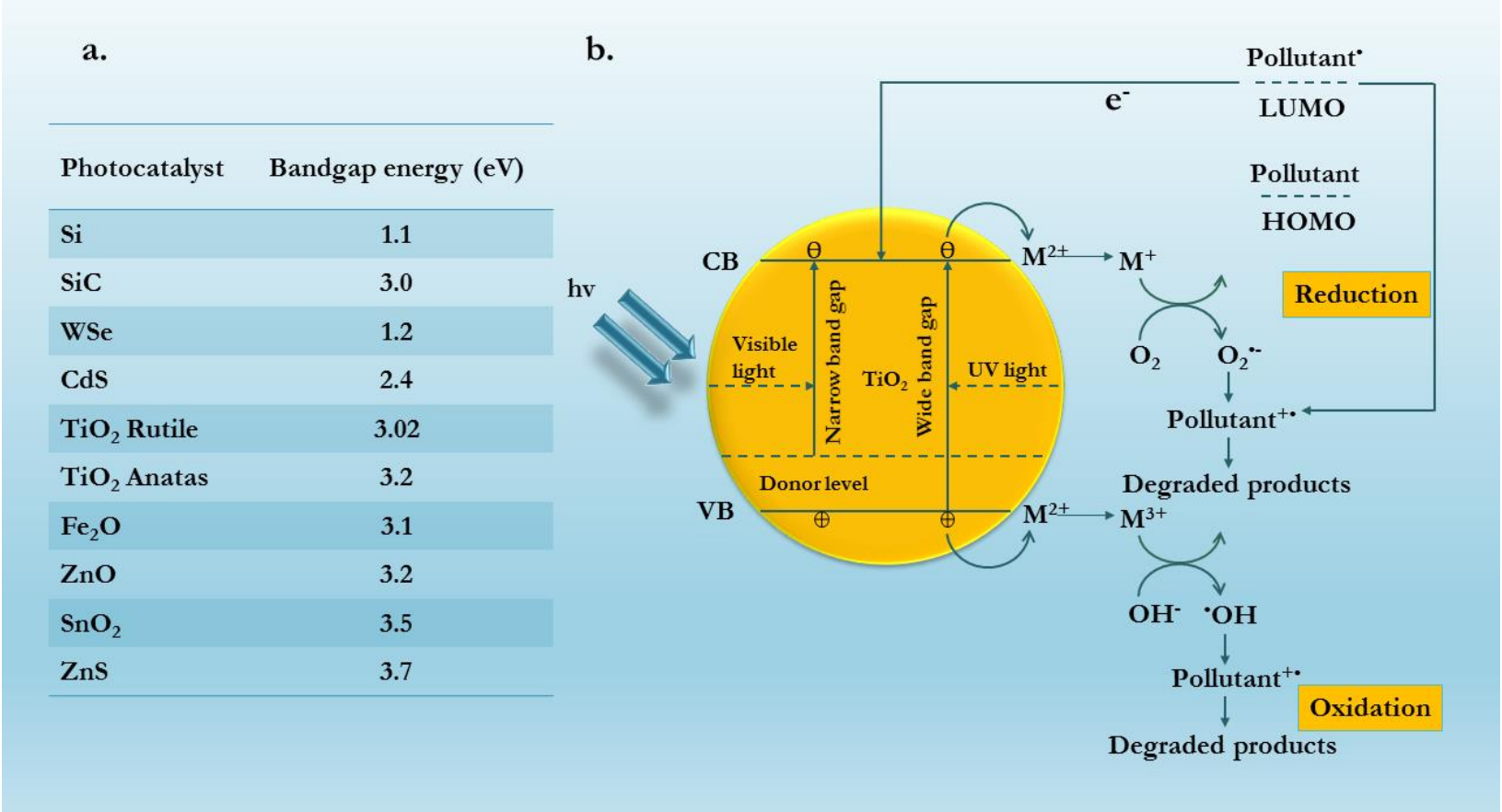

Fig 7. a. band gap energies of some semiconducter materials used in photocatalysis application and $b$. photooxidative degradation of organic pollutants by using $\mathrm{TiO}_{2}$ nanoparticles [45].

\section{Synthesis of undoped and doped nanoparticles used in photocatalysis applications}

Photocatalysis is an advanced oxidation process that is sustainable in treating and purifying water relying on nanomaterials, especially in modern technologies. The principle of photocatalysis work on the oxidative elimination of micro pollutants, organic pollutants and microbes and their degradation. Preparation of nanoparticles from metal and nonmetal doping [56], co-doping (with metal-metal, metal-nonmetal, and nonmetal-nonmetal) [57], and doping with different components confined to the tri-doping system to get better chemical and physical properties [58]. Herein, a historical survey of some recent reteaches about the topic of preparations of catalysis that reported in the last five years:

In 2016, According to Singh and Hankins, membrane technology has the potential of bridging the economical and sustainability gap, amid possibilities of low or no chemical usage, environmental friendliness and easy accessibility to many. That is, membrane technology has proven to be a more favorable option in wastewater treatment processes in recent times [59].

In 2016, D. Ahirwar et al. have synthesized a highly crystallinity, porosity and purity mesoporous- $\mathrm{TiO}_{2}$ catalyst without using an acidic solution or a base by a modified sol-gel methodology. The researchers have gained a specific surface area about $226.25 \mathrm{~m}^{2} / \mathrm{g}$, while 
about 186, 210 and $192 \mathrm{~m}^{2} / \mathrm{g}$ by deblock copolymers Lutensol AT18, Lutensol AT25 and Lutensol AT50, respectively [60] .

In 2016, X. Chem et al. have synthesized a mesoporous- $\mathrm{TiO}_{2}$ by using the reactant $\mathrm{TiCl}_{4}$ and the biological source lignin as a template. The researchers have gained a surface area about $165.8 \mathrm{~m}^{2} / \mathrm{g}$ and a porosity volume of $0.312 \mathrm{~cm}^{3} / \mathrm{g}$ by hydrolysis/precipitation methodology. The researchers have interpreted that the crystal size obtained and the mesoporous- $\mathrm{TiO}_{2}$ structure is because of the two hydroxyl groups of lignin and surface hydroxyl resins of $\mathrm{TiO}_{2}$ precursors were interacted [61].

In 2017, T. Kamal et al. have prepared porous cellulose acetate fiber by wet spinning technique and cellulose acetate sheets by doctor blade (tape casting) technique to produce a material with large surface area. They have synthesized silver (Ag) nanoparticles on immobilizing substrate by dipped both of cellulose acetate fiber and sheets in $0.1 \mathrm{M}$ of aqueous $\mathrm{AgNO}_{3}$ and treated them with $0.1 \mathrm{M}$ of $\mathrm{NaBH}_{4}$. The prepared materials were examined and utilized as catalysts. The Ag/cellulose acetate fiber assumed to be better catalysis in the hydrogenation process of 2,6- dinitrophenol when contrasted with the $\mathrm{Ag} /$ cellulose acetate sheets [62].

In 2017, S. Toston et al. have used super-crucial $\mathrm{CO}_{2}$ to prepare the photocatalyst $0.1 \mathrm{wt} \%$ $\mathrm{Pt}_{-\mathrm{TiO}} 2$ in. the purpose of their study is to use the photocatalysis for reducing $\mathrm{CO}_{2}$ into methane; the rate of methane production was $0.245 \mu \mathrm{mol} / \mathrm{g}$-cat $/ \mathrm{h}$. The obtained photocatalyst characterized by crystalline structure, large surface area, porosity and able to absorb light in visible [63].

In 2018 , B. Niu et al. have studied the mesoporous- $\mathrm{TiO}_{2}$ due to its internal porosity and high surface area. They studied the mesoporous- $\mathrm{TiO}_{2}$ applications, especially in the field of photocatalysis, and explained its synthesis methods, including the sol-gel method, hydrothermal and solvothermal and others. The particles size of 70-110 nm of $\mathrm{TiO}_{2}$ nanoparticles have prepared in a supercritical carbon dioxide system by hydrolysis of titanium tetraisopropoxide (TTIP) [64].

In 2018, G. Liao et al. have reported a preparation of a nanocomposite of Ag nanoparticles with poly (styrene-N-isopropyl acrylamide-methacrylic acid). The prepared nanocomposite was examined as catalyst and they approved its efficiency and stability to reduce and absorb the methylene blue dye. Ag nanoparticles showed highly superior to their bulk due to their antimicrobial and physicochemical characteristics and their mechanical properties [65].

In 2018, Lang et al. manufactured an Ag-rGO-TiO 2 nanocomposite by depositing $\mathrm{Ag}$ nanocubes and $\mathrm{TiO}_{2}$ nanolayers on reduced graphene oxides surfaces. Besides, they have prepared $\mathrm{Ag}-\mathrm{TiO}_{2}$ for comparing process. They noticed no photocatalytic activity for $\mathrm{Ag}-\mathrm{TiO}_{2}$ and $\mathrm{TiO}_{2}$ while the Ag-rGO-TiO 2 nanocomposite has provided a hydrogen rate of $0.53 \mu \mathrm{mol} \mathrm{g}^{-1}$ $\mathrm{h}^{-1}$ per mass unit under visible light with methanol water (20 vol\% methanol). Moreover, a formed Schottky barrier on $\mathrm{rGO}^{-\mathrm{TiO}_{2}}$ surface reinforced the hot electron spreading from rGO to $\mathrm{TiO}_{2}[66]$. 
In 2019, X. Lin et al. have reported a synthesis method of a ternary heterostructure photocatalyst. The synthesis procedure included a co-anchoring process of the carbon nitride quantum dot and nitrogen-doped carbon quantum dot (CNQD and NCD) on $\mathrm{BiVO}_{4}$ microspheres surfaces. The synthesized compound exhibited an excellent activity under visible light as a photocatalyst to degrade a rhodamine B dye and tetracycline antibiotic. They have observed that $\mathrm{BiVO}_{4} / \mathrm{CNQDs} / \mathrm{NCDs}$ showed better photoreactivity for degrading both $\mathrm{RhB}$ and TC if compared with pure samples. This study provided a useful results of ternary heterostructure photocatalysts application in water purification [67].

In 2019, M. Taherinia et al. have prepared a doped- $\mathrm{TiO}_{2}$ nanoparticles by sol-gel method and studied their photocatalytic activity at 450,550 and $650{ }^{\circ} \mathrm{C}$ calcination temperature. The gained findings showed that the doped- $\mathrm{TiO}_{2}$ nanoparticles have increased surface reactivity when they solve the Ti precursor with acetic acid. A reduced photocatalytic activity of doped$\mathrm{TiO}_{2}$ was observed at the higher levels of temperature. This is due to the fact that the nanoparticles accumulate together, which leads to reduced surface area [68].

In 2019, Q. Gao et al. have manufactured a hydrogenated F-doping $\mathrm{TiO}_{2}$ using a two-step facial method. The researchers approved that the F-doping improved the UV-absorption by $\mathrm{TiO}_{2}$ and it can be increased by hydrogen treatment in visible region. Accordingly, the hydrogenated F-doping $\mathrm{TiO}_{2}$ showed preferred photocatalytic properties over pure, hydrogenated or F-doped $\mathrm{TiO}_{2}$, in either hydrogen generating or organic contaminant degradation [69].

In 2020, Z. Wanga et al. have presented an investigation of carbamazepine (CBZ) photocatalytic degradation by neodymium-doped antimony trioxide/titanium dioxide (Nddoped $\mathrm{Sb}_{2} \mathrm{O}_{3}-\mathrm{TiO}_{2}$ ) inside ultrapure water under UVC radiation. They have synthesized the catalyst samples by hydrothermal technique with $0-2 \%$ ratios of $\mathrm{Nd}$. The obtained measured surface area at $1 \% \mathrm{Nd}=9.56 \mathrm{~m}^{2} \mathrm{~g}^{-1}$ and the band gap energy $=3 \mathrm{eV}$. As a result from this experiment, $1 \% \mathrm{Nd}$-doped $\mathrm{Sb}_{2} \mathrm{O}_{3} / \mathrm{TiO}_{2}$ photocatalyst at catalyst dose of $0.5 \mathrm{~g} / \mathrm{L}$ demonstrated the best photocatalytic action towards CBZ degradation. Finally, from quenching and trapping tests on each sample, it has been shown that $\mathrm{OH}$ radicals and ${ }^{\circ} \mathrm{O}_{2}$ - were in charge of $\mathrm{CBZ}$ degradation [70].

In 2020, C. Noda et al. have synthesized a three component photocatalyst namely $\mathrm{C}_{3} \mathrm{~N}_{4} / \mathrm{rGO} / \mathrm{C}-\mathrm{TiO}_{2}$ by the in-situ methodology. $\mathrm{C}_{3} \mathrm{~N}_{4} / \mathrm{rGO}$ increased the surface contact and C$\mathrm{TiO}_{2}$ has crystallized over the mentioned surface to get a highly dispersed nanoparticles on $\mathrm{C}_{3} \mathrm{~N}_{4} / \mathrm{rGO}$ surface. The most efficient and higher photocatalytic activity was obtained by the samples produced by in-situ method. By measuring the transient absorption, they found that the composite has possessed the longer life time than other components which provide it the ability to exhibit higher activity in photocatalytic response [71].

In 2020, Becerra et al. have adopted the aerobic biological treatment as a secondary treatment after photocatalytic treatment of water contaminated with hlorpyrifos (insecticide), the results showed that the biological treatment chosen had a high removal efficiency [72]. 


\section{Conclusion:}

Nanotechnology has gained a momentum globally for water treatment. The extraordinary properties of nanomaterials and their assembly with momentum treatment advances present incredible chances in water treatment purposes. Numerous numbers of nanotechnologies are still in lab explore stage, some have advanced toward pilot testing or even commercialization. Among them, three classes appear to be a promise category in full scale application sooner rather than later dependent on their researching, developing, traditional accessibility and cost of the involved nanomaterials: nano-adsorbents, nanotechnology enabled membrane and nano-photocatalysts. Every one of the three classifications have commercial items, in spite of the fact that they have not been applied in huge scope of treating water. There are several methods that have been applied to the purification and treatment of water and the removal of organic and inorganic pollutants from it. These techniques were chosen according to their effectiveness and the simple tools required in them. These technologies and their limitations were explained in this review. The most acceptable methods are nanofiltration and microfiltration membrane methods. Nanofiltration requires low operating presser to provide high and high of permeate flux when using this membrane as a separation barrier. On the other hand, due to low pressure requirement in microfiltration membrane process, this method considered as an attractive separation technique for undesired particle removal in water purification processes. We conclude that it is necessary to have cooperation between industrial companies and research and development centers in order to get rid of the challenges facing nanotechnology, including the high cost problems and risks that affect the environment, nature and human health.

\section{Information on Author affiliations:}

Khalida F.AL-Azawi (Applied Chemistry Division, Applied Science Department, University of Technology,Iraq)

Shaimaa AL-Baghdadi (Energy and Renewable Energies Technology Centre, University of Technology , Iraq)

Shemaa A. Soud*(Biotechnology Division, Applied Science Department, University of Technology, Iraq) (100234@uotechnology.edu.iq)

\section{References}

[1] Giri, S., \& Qiu, Z. (2016). Understanding the relationship of land uses and water quality in twenty first century: a review. J Environ Manag, 173, 41-48. doi:10.1016/j.jenvman.2016.02.029

[2] Buratti, F. M., Manganelli, M., \& Vichi, S. (2017). Cyanotoxins: producing organisms, occurrence, toxicity, mechanism of action and human health toxicological risk evaluation. Arch Toxicol, 91, 1049-1130. doi:10.1007/s00204-016-1913-6

[3] Ali, H., Khan, E., \& Ilahi, I. (2019). Environmental chemistry and ecotoxicology of hazardous heavy metals: Environmental persistence, toxicity, and bioaccumulation. Journal of Chemistry, 2019, 1-14. doi:https://doi.org/10.1155/2019/6730305

[4] Healthy Environment, Healthy People. (2014). World Health Organization (WHO), Public Health, Environmental and Social Determinant of Health (PHE), (63).

[5] Bolong, N., Ismail, A., Salim, M., \& Matsuura, T. (2009). A review of the effects of emerging contaminants in wastewater and options for their removal. Desalination, 239, 229-246. doi:10.1016/j.desal.2008.03.020 
[6] Valentìn, L., Nousiainen, A., \& Mikkonen, A. (2013). Fungal-mediated degradation of emerging pollutants in sewage sludge," in Emerging Organic Contaminants in Sludges: Analysis, Fate and Biological Treatment. In T. Vicent, G. Caminal, \& E. Eljarrat (Eds.), Handbook of Environmental Chemistry (24th ed., pp. 1-30). Berlin: Springer-Verlag. doi:10.1007/698_2012_208

[7] Schell, L. M., Knutson, K. L., \& Bailey, S. (2012). Environmental Effects on Growth. In Human Growth and Development (2nd ed.). doi:10.1016/B978-0-12-383882-7.00010-6

[8] Rasalingam, S., Peng, R., \& Koodali, R. T. (2014). Removal of Hazardous Pollutants from Wastewaters: Applications of $\mathrm{TiO}_{2}-\mathrm{SiO}_{2}$ Mixed Oxide Materials. Journal of Nanomaterials, 2014, 1-42. doi:10.1155/2014/617405

[9] Zheng, C., Zhao, L., Zhou, X., Fu, Z., \& Li, A. (2013). Treatment Technologies for Organic Wastewater, Water Treatment, Walid Elshorbagy and Rezaul Kabir Chowdhury, IntechOpen. doi:10.5772/52665.

[10] Aktar, M., Sengupta, D., \& Chowdhury, A. (2009). Impact of pesticides use in agriculture: their benefits and hazards. Interdisciplinary Toxicology, 2(1), 1-12. doi:https://doi.org/10.2478/v10102-009-0001-7

[11] Hai, F., Tessmer, K., Nguyen, L., Kang, J., Price, W., \& Nghiem, L. (2011). Removal of micropollutants by membrane bioreactor under temperature variation. J Membr Sci, 383, 144-151. doi:10.1016/j.memsci.2011.08.047

[12] Rehan, Z. A., Muhammad, Z., Saba, A., Rashid, A., \& Abdul, R. (2020). Prospects of nanocomposite membranes for water treatment by pressure-driven membrane processes. In Nanocomposite Membranes for Water and Gas Separation (pp. 237-256). Micro and Nano Technologies. doi:https://doi.org/10.1016/B978-0-12-816710-6.000109

[13] Filippov, A., Starov, V., Llyod, D., Chakravarti, S., \& Glaser, S. (1994). Sieve mechanism of microfiltration. Journal of Membrane Science, 89, 199-213. doi:10.1016/03767388(94)80102-9

[14] Gao, Q., Si, F., Zhang, S., Fang, Y., Chen, X., \& Yang, S. (2019). Hydrogenated F-doped $\mathrm{TiO}_{2}$ for photocatalytic hydrogen evolution and pollutant degradation. Int. J. Hydrogen Energy, 44, 8011-8019. doi:10.1016/j.ijhydene.2019.01.233

[15] Badruzzaman, M., Voutchkov, N., Weinrich, L., \& Jacangelo, J. (2019). Selection of pretreatment technologies for seawater reverse osmosis plants: A review. Desalination, 449, 78-91. doi:https://doi.org/10.1016/j.desal.2018.10.006

[16] Petersen, R. (1993). Composite reverse osmosis and nanofiltration membranes. Journal of Membrane Science, 83, 81-150. doi:10.1016/s0376-7388(93)80014-o

[17] Bodzek, M., Konieczny, K., \& Kwiecińska-Mydlak, A. (2019). Nanotechnology in water and wastewater treatment. Graphene - the nanomaterial for next generation of semipermeable membranes. Critical Reviews in Environmental Science and Technology, 165. doi:10.1080/10643389.2019.1664258

[18] Abdelbasir, S. M., \& Shalan, A. E. (2019). An overview of nanomaterials for industrial wastewater treatment. Korean Journal of Chemical Engineering, 36(8), 1209-1225. doi:10.1007/s11814-019-0306-y

[19] Tlili, I., \& Alkanhal, T. A. (2019). Nanotechnology for water purification: electrospun nanofibrous membrane in water and wastewater treatment. Journal of Water Reuse and Desalination, 9(3), 232-248. doi:10.2166/wrd.2019.057

[20] Sikora, A., Shard, A. G., \& Minelli, C. (2016). Size and ל-Potential Measurement of Silica 
Nanoparticles in Serum Using Tunable Resistive Pulse Sensing. Langmuir, 32, 2216-2224. doi:10.1021/acs.langmuir.5b04160

[21] Ojea-Jiménez, I., López, X., Arbiol, J., \& Puntes, V. (2012). Citrate-coated gold nanoparticles as smart scavengers for mercury(II) removal from polluted waters. ACS Nano., 6, 2253. doi:10.1021/nn204313a

[22] Khan, I., Saeed, K., \& Khan, I. (2019). Nanoparticles: Properties, applications and toxicities. Arabian Journal of Chemistry, 12(7), 908-931. doi:10.1016/j.arabjc.2017.05.011

[23] Qu, X., Alvarez, P. J. J., \& Li, Q. (2013). Applications of nanotechnology in water and wastewater treatment. Water Research, 47(12), 3931-3946. doi:10.1016/j.watres.2012.09.058

[24] Iravani, S. (2011). Green synthesis of metal nanoparticles using plants. Green Chem., 13, 2638.

[25] Mishra, A., Basu, S., Shetti, N. P., Reddy, K. R., \& Aminabhavi, T. M. (2019). Photocatalysis of Graphene and Carbon Nitride-Based Functional Carbon Quantum Dots. In Nanoscale Materials in Water Purification (pp. 759-781). Micro and Nano Technologies. doi:https://doi.org/10.1016/B978-0-12-813926-4.00035-5

[26] Gandhi, M. R., Vasudevan, S., Shibayama, A., \& Yamada, M. (2016). Graphene and Graphene-Based Composites: A Rising Star in Water Purification - A Comprehensive Overview. Chem Europe, 1(15), 4358-4385.

[27] Ihsanullah, Abbas, A., Al-Amer, A. M., Laoui, T., Al-Marri, M. J., Nasser, M. S., ... Atieh, M. A. (2016). Heavy metal removal from aqueous solution by advanced carbon nanotubes: Critical review of adsorption applications. Separat. Purif. Technol., 157, 141-161. doi:10.1016/j.seppur.2015.11.039

[28] Wang, Y., Guo, L., Qi, P., Liu, X., \& Wei, G. (2019). Synthesis of three-dimensional graphene-based hybrid materials for water purification: A review. Nanomaterials, 9(8), 1-31. doi:10.3390/nano9081123

[29] Ealias, A. M., \& Saravanakumar, M. P. (2017). A review on the classification, characterisation, synthesis of nanoparticles and their application. IOP Conference Series: Materials Science and Engineering, 263(3), 1-15. doi:10.1088/1757-899x/263/3/032019

[30] Wick, P., Manser, P., \& Limbach, L. K. (2007). The degree and kind of agglomeration affect carbon nanotube cytotoxicity. Toxicology Letters, 168(2), 121-131. doi:10.1016/j.toxlet.2006.08.019

[31] Jiang, G., Lin, Z., Chen, C., Zhu, L., Chang, Q., Wang, N., Tang, H. (2011). TiO2 nanoparticles assembled on graphene oxide nanosheets with high photocatalytic activity for removal of pollutants. Carbon N Y, 49, 2693-2701. doi:10.1016/j.carbon.2011.02.059

[32] Kim, J., Davies, S. H. R., Baumann, M. J., Tarabara, V. V., \& Masten, S. J. (2008). Effect of ozone dosage and hydrodynamic conditions on the permeate flux in a hybrid ozonationceramic ultrafiltration system treating natural waters. Journal of Membrane Science, 311(1-2), 165-172. doi:10.1016/j.memsci.2007.12.010

[33] Chae, S.-R., Wang, S., Hendren, Z. D., Wiesner, M. R., Watanabe, Y., \& Gunsch, C. K. (2009). Effects of fullerene nanoparticles on Escherichia coli K12 respiratory activity in aqueous suspension and potential use for membrane biofouling control. Journal of Membrane Science, 329(1-2), 68-74. doi:10.1016/j.memsci.2008.12.023

[34] Amin, M. T., Alazba, A. A., \& Manzoor, U. (2014). A Review of Removal of Pollutants from Water/Wastewater Using Different Types of Nanomaterials. Advances in Materials 
Science and Engineering, 2014, 1-24. doi:http://dx.doi.org/10.1155/2014/825910

[35] Jiang, T., Yan, L., Zhang, L., Li, Y., Zhao, Q., \& Yin, H. (2015). Fabrication of a novel graphene oxide/ $\beta$-FeOOH composite and its adsorption behavior for copper ions from $\begin{array}{llll}\text { aqueous } \quad \text { solution. } & \text { Talt }\end{array}$ doi:https://doi.org/10.1039/C5DT01030F

[36] Xu, L., \& Wang, J. (2017). The application of graphene-based materials for the removal of heavy metals and radionuclides from water and wastewater. Crit. Rev. Environ. Sci. Technol., 47, 1042-1105. doi:https://doi.org/10.1080/10643389.2017.1342514

[37] Ezugbe, E. O. and Rathilal, S. (2020). Membrane Technologies in Wastewater Treatment: A Review. Membranes, 10(89), 1-28. doi:10.3390/membranes10050089

[38] Fard, A. K., McKay, G., Buekenhoudt, A., Al Sulaiti, H., Motmans, F., Khraisheh, M., \& Atieh, M. (2018). Inorganic membranes: Preparation and application for water treatment and desalination. Materials, 11(74), 1-47. doi:10.3390/ma11010074

[39] Jiang, S., Chen, Y., Duan, G., Mei, C., Greiner, A., \& Agarwal, S. (2018). Electrospun nanofiber reinforced composites: A review. Polymer Chemistry, 9, 2685-2720. doi:https://doi.org/10.1039/C8PY00378E.

[40] Anand, A., Unnikrishnan, B., Mao, J., Lin, H., \& Huang, C. (2018). Graphene-based nanofiltration membranes for improving salt rejection, water flux and antifouling-A review. Desalination, 429, 119-133. doi:https://doi.org/10.1016/j.desal.2017.12.012

[41] Shirazi, M. M. A., Bazgir, S., \& Meshkani, F. (2020). Electrospun Nanofibrous Membranes for Water Treatment. In A. Abdelrasoul (Ed.). doi:10.1016/j.cherd.2020.09.030

[42] Said, I. A., Chomiak, T., Floyd, J., \& Li, Q. (2020). Sweeping gas membrane distillation (SGMD) for wastewater treatment, concentration, and desalination: A comprehensive review. Chemical Engineering and Processing - Process Intensification 107960. doi:10.1016/j.cep.2020.107960

[43] Saleh, I. A., Zouari, N., \& Al-Ghouti, M. A. (2020).Removal of pesticides from water and wastewater: Chemical, physical and biological treatment approaches. Environmental Technology \& Innovation, 101026. doi:10.1016/j.eti.2020.101026

[44] Fane, A. (2018). A grand challenge for membrane desalination: More water, less carbon. Desalination, 426, 155-163. doi:10.1016/j.desal.2017.11.002

[45] Baloyi, J., Seadira, T., Raphulu, M., \& Ochieng, A. (2015). Preparation, characterization and growth mechanism of dandelion-like $\mathrm{TiO}_{2}$ nanostructures and their application in photocatalysis towards reduction of Cr (VI). Materials Today: Proceedings, 2(7), 39733987. doi:10.1016/j.matpr.2015.08.027

[46] Tasbihi, M., Călin, I., Šuligoj, A., Fanetti, M., \& Lavrenčič, Š. U. (2017). Photocatalytic degradation of gaseous toluene by using $\mathrm{TiO}_{2}$ nanoparticles immobilized on fiberglass cloth. Journal of Photochemistry and Photobiology A: Chemistry, 336, 89-97. doi:10.1016/j.jphotochem.2016.12.025

[47] Moma, J., \& Baloyi, J. (2018). Modified Titanium Dioxide for Photocatalytic Applications, Photocatalysts - Applications and Attributes. (S. B. Khan \& K. Akhtar, Eds.), IntechOpen. doi:10.5772/intechopen.79374

[48] Kaviyarasu, K., Geetha, N., Kanimozhi, K., Magdalane, C., \& Sivaranjani, S Ayeshamariam, A. (2017). In vitro cytotoxicity effect and antibacterial performance of human lung epithelial cells A549 activity of zinc oxide doped $\mathrm{TiO}_{2}$ nanocrystals: Investigation of biomedical application by chemical method. Materials Science and Engineering: C., 74, 325333. doi:10.1016/j.msec.2016.12.024 
[49] Smith, Y. R., Ray, R. S., Carlson, K., Sarma, B., \& Misra, M. (2013). Self-Ordered Titanium Dioxide Nanotube Arrays: Anodic Synthesis and Their Photo/Electro-Catalytic Applications. Materials, 6(7), 2892-2957. doi:10.3390/ma6072892

[50] Ollis, D. (2005). Kinetics of liquid phase photocatalyzed reactions: An illuminating approach. J. Phys. Chem. B, 109, 2439-2444. doi:10.1021/jp040236f

[51] Al Jitan, S., Palmisano, G., \& Garlisi, C. (2020). Synthesis and surface modification of $\mathrm{TiO}_{2-}$ based photocatalysts for the conversion of $\mathrm{CO}_{2}$. Catalysts, 10(2). ; doi:10.3390/catal10020227

[52] Konstantinou, I., \& Albanis, T. (2004). TiO2-assisted photocatalytic degradation of azo dyes in aqueous solution: Kinetic and mechanistic investigations. A review. Appl. Catal. $B$ Environ., 49, 1-14. doi:10.1016/j.apcatb.2003.11.010

[53] Miszczak, S., \& Pietrzyk, B. (2015). Anatase-rutile transformation of $\mathrm{TiO}_{2}$ sol-gel coatings deposited on different substrates. Ceram. Int., 41, 7461-7465. doi:10.1016/j.ceramint.2015.02.066

[54] Hanaor, D. A. H., \& Sorrell, C. C. (2011). Review of the anatase to rutile phase transformation. J Mater Sci, 46, 855-874. Hanaor, D. A. H., \& Sorrell, C. C. (2010). Review of the anatase to rutile phase transformation. Journal of Materials Science, 46(4), 855874. doi:10.1007/s10853-010-5113-0

[55] Bellardita, M., Di Paola, A., García-López, E., Loddo, V.; Marcì, G., \& Palmisano, L. (2013). Photocatalytic $\mathrm{CO}_{2}$ reduction in gas-solid regime in the presence of bare, $\mathrm{SiO}_{2}$ supported or $\mathrm{Cu}$-loaded $\mathrm{TiO}_{2}$ samples. Curr. Org. Chem., 17, 2440-2448.

[56] Babic, B., Zarubica, A., Arsić, T. M., Maletaskic, J., Jokić, B., Abazović, N., \& Matovic, B. (2015). Iron doped anatase for application in photocatalysis. Journal of the European Ceramic Society, 36(12). doi:http://dx.doi.org/10.1016/j.jeurceramsoc.2015.11.031

[57] Lü, X., Liu, J., Zhang, H., Ding, J., \& Xie, J. (2009). Structure and property of mesoporous molybdenum/carbon co-doped brookite titania. Trans. Nonferrous Met. Soc., 19, 669-673.

[58] Luca, D., Mardare, D., Iacomi, F., \& Teodorescu, C. M. (2006). Increasing surface hydrophilicity of titania films by doping. Appl. Surf. Sci., 252, 6122-6126. doi:10.1016/j.apsusc.2006.05.011

[59] Singh, R., Hankins, N. (2016). Emerging Membrane Technology for Sustainable Water Treatment; Elsevier: Amsterdam, The Netherlands,.

[60] D. Ahirwar, M. Bano, and F. Khan, "Synthesis of mesoporous $\mathrm{TiO}_{2}$ and its role as a photocatalyst in degradation of indigo carmine dye," J. Sol-Gel Sci. Technol., vol. 79, pp. 228-237, 2016.

[61] Chen, X., Kuo, D.-H., Lu, D., Hou, Y., \& Kuo, Y. (2016). Synthesis and photocatalytic activity of mesoporous $\mathrm{TiO}_{2}$ nanoparticle using biological renewable resource of un-modified lignin as a template. Microporous and Mesoporous Materials, 223, 145-151. doi:10.1016/j.micromeso.2015.11.005

[62] Kamal, T., Ahmad, I., Bahadar, S. K., \& Abdullah, M. A. (2017). Synthesis and catalytic properties of silver nanoparticles supported on porous cellulose acetate sheets and wetspun fibers. Carbohydrate Polymers, 157, 294-302. doi:10.1016/j.carbpol.2016.09.078

[63] Tostón, S., Camarillo, R., Martínez, F., Jiménez, C., \& Rincón, J. (2017). Supercritical synthesis of platinum-modified titanium dioxide for solar fuel production from carbon dioxide. Chin. J. Catal., 38, 636-650. doi:10.1016/s1872-2067(17)62766-9

[64] Niu, B., Wang, X., Wu, K., He, X., \& Zhang, R. (2018). Mesoporous Titanium Dioxide: Synthesis and Applications in Photocatalysis, Energy and Biology. Materials, 11(10), 
1910. doi:10.3390/ma11101910

[65] Liao, G., Li, Q., Zhao, W., Pang, Q., Gao, H., \& Xu, Z. (2018). In-situ construction of novel silver nanoparticle decorated polymeric spheres as highly active and stable catalysts for reduction of methylene blue dye. Applied Catalysis A: General, 549, 102-111. doi:10.1016/j.apcata.2017.09.034

[66] Lang, Q., Chen, Y., Huang, T., Yang, L., Zhong, S., Wu, L., ... Bai, S. (2018). Graphene "bridge” in transferring hot electrons from plasmonic ag nanocubes to $\mathrm{TiO}_{2}$ nanosheets for enhanced visible light photocatalytic hydrogen evolution. Appl. Catal. B, 220, 182-190. doi:10.1016/j.apcatb.2017.08.045

[67] Lin, X., Liu, C., Wang, J., Yang, S., Shi, J., \& Hong, Y. (2019). Graphitic carbon nitride quantum dots and nitrogen-doped carbon quantum dots co-decorated with BiVO4 microspheres: A ternary heterostructure photocatalyst for water purification. Separation and Purification Technology, 226, 117-127. doi:10.1016/j.seppur.2019.05.093

[68] Taherinia, M., Nasiri, M., \& Abedini, E. (2019). Influence of calcination temperature and solvent of titanium precursor on the photocatalytic activity of $\mathrm{N}$-doped $\mathrm{TiO}_{2}$ nanoparticles in $\mathrm{H}_{2}$ evolution under visible radiation. Environ Dev Sustain, 21, 1963-1975. doi:10.1007/s10668-018-0114-2

[69] Gao, Q., Si, F., Zhang, S., Fang, Y., Chen, X., \& Yang, S. (2019). Hydrogenated F-doped $\mathrm{TiO}_{2}$ for photocatalytic hydrogen evolution and pollutant degradation. Int. J. Hydrogen Energy, 44, 8011-8019. doi:10.1016/j.ijhydene.2019.01.233

[70] Wanga, Z., Srivastava, V., Wang, S., Sun, H., Thangaraj, S. K., Jänis, J., \& Sillanpää, M. (2020). UVC-assisted photocatalytic degradation of carbamazepine by $\mathrm{Nd}$-doped $\mathrm{Sb}_{2} \mathrm{O}_{3} / \mathrm{TiO}_{2}$ photocatalyst. Journal of Colloid and Interface Science, 562, 461-469. doi:https://doi.org/10.1016/j.jcis.2019.11.094

[71] Noda, C., Asakura, Y., Shiraki, K., Yamaka, A., \& Yin, S. (2020). Synthesis of threecomponent $\mathrm{C}_{3} \mathrm{~N}_{4} / \mathrm{rGO} / \mathrm{C}-\mathrm{TiO}_{2}$ photocatalyst with enhanced visible-light responsive photocatalytic deNOx activity. Chemical Engineering Journal, 390, 124616. doi:10.1016/j.cej.2020.124616

[72] Becerra, D., Arteaga, B. L., Ochoa, Y. E., Barajas-Solano, A. F., García-Martínez, J. B., \& Ramírez, L. F. (2020). Coupling of heterogeneous photocatalysis and aerobic biological process of activated sludge to treat wastewater containing Chlorpyrifos. Ingeniería y competitividad, 22(1), 8135. doi: http://dx.doi.org/10.25100/iyc.v22vi1i.8135 
تطبيقات المواد النانوية في تثنية المياه: مراجعة

خالدة فرحان سهيل1، شيماء باسم خلف2، شيماء عبد الستار سعود3 *

1- فرع الكيمياء التطبيقية، قسم العلوم التطبيقية، الجامعة التكنولوجية

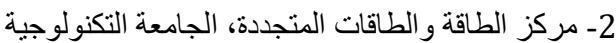

3- فرع التقنيات الاحيائية ،قسم العلوم التطبيقية،الجامعة التكنولوجية (100234@uotechnology.edu.iq)

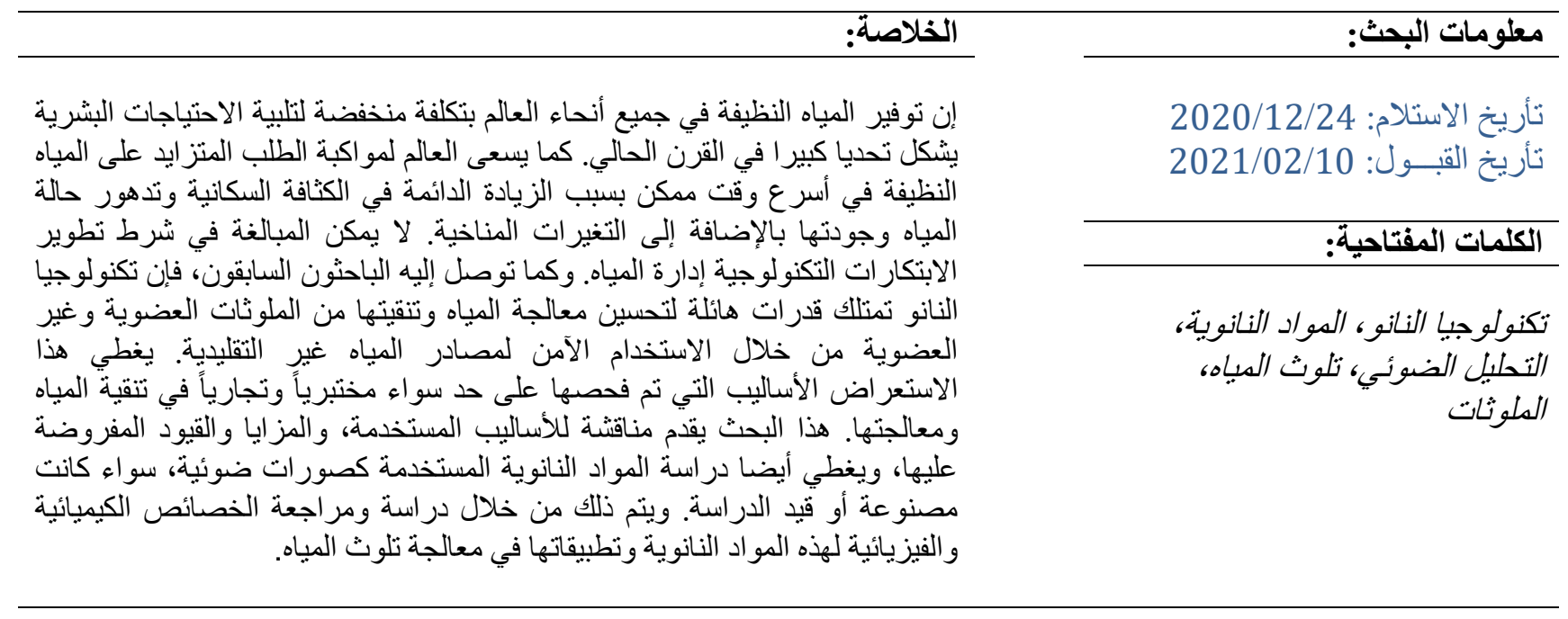

